\title{
An experimental study on the behaviour of GFRP pultruded I beam reinforced with CFRP laminates
}

\author{
G.Ganesan $^{1 *}$ and G.Kumaran ${ }^{2}$ \\ Research Scholar, Department of Civil and Structural Engineering, Annamalai University, Annamalai Nagar, Tamil \\ Nadu, India ${ }^{1}$ \\ Professor, Department of Civil and Structural Engineering, Annamalai University, Annamalai Nagar, Tamil Nadu, \\ India $^{2}$
}

\section{(C2018 ACCENTS}

\begin{abstract}
Glass fibre reinforced polymers (GFRP) pultruded profiles are being widely used as a structural material in the construction industry, particularly in a corrosive environment as an alternative material for steel. Despite its many advantages, their design is limited by deformation in service limit states and by local and global buckling in ultimate limit states. To overcome these limitations, they can be reinforced with carbon fiber reinforced polymer (CFRP) laminates. In this exploration, the structural behaviour of GFRP pultruded profiles reinforced with CFRP laminates on the flanges has been observed. The mechanical properties are obtained from the specimen extracted from the flanges. Tests of three-point and four-points twisting have been conducted with different layup sequence of CFRP laminates, on full-scale models. A comparative study is made with experimental and analytical results.
\end{abstract}

\section{Keywords}

Glass fibre reinforced plastic, Pultruded profiles, Flexural stiffness, Local buckling.

\section{Introduction}

In the construction industry, due to the advantages like light weight, high power, resistance to decay etc., usage of fibre-reinforced polymers (FRP) pultruded profiles have gained a wide application. Recently, they are widely being used in the construction of bridge systems, walkways and other structures which are brought into light to corrosive environment.

The procedure of unidirectional filaments along with other fabric mats impregnating in resin is known as pultrusion which is basically a manufacturing process. This is later pulled through a heated die to produce long prismatic components with a constant cross-section. The thick structural component with a small number of reinforcement layers are pultruded composite plates and beams.

GFRP profiles are commonly used in construction due to the low cost of glass fibres. Since GFRP profiles have relatively low elastic moduli, it is often administered by limitations in change at service load levels or by bucking, in case of thin-walled sections, instead of ultimate strength limits.

*Author for correspondence

232
Despite their many advantages, the model of GFRP pultruded profiles is governed by deformation in service limit states and by local and global buckling in ultimate limit states. To overcome these limitations, GFRP profiles are reinforced with CFRP laminates of different layup sequence.

For the design of composite structures made of pultruded profiles, Davalos and Qiao [1] explained that both rigidity and strength are equally significant and depend on the material and on the element crosssection.

The laminate of different fibre orientation of advanced composite materials may display complex anisotropic behaviour. The section walls of profiles fabricated by pultrusion process feasibly simulated as laminated composites with comparable orthotropic mechanical properties in their longitudinal and transverse directions.

While changes in the profile section geometry are easily related to changes in the stiffness, changes in the material and fibre orientation are not so obvious to be evaluated. Bank [2] show that, the longitudinal elastic modulus obtained from a flexural test on a FRP pultruded profile is dissimilar from the one 
achieved from a flexural test on a solid bar coupon extracted from the same profile. This happens due to the difference in mechanical properties between a full size profile of thin walled section and a solid bar of rectangular section. But, Meier et al. [3] stated that reliable values of elastic moduli for FRP beams can be got by conducting tests on small coupons which have been extracted from pultruded profiles. Due to this deviation on research findings, Kumar et al. [4], suggested to conduct more experimental tests and researches about the behaviour of full-size pultruded beams and also of coupons which has been extracted from these beams.

The aim of this study is to figure out the behaviour of GFRP pultruded beams through experiment and analysis. In the experimental programme, two sets of beams of the equal cross section, i.e., $200 \times 100 \times$ $8 \mathrm{~mm}$, reinforced with CFRP laminates of difference layup sequence are considered.

\section{Timoshenko beam theory}

A designer who requires obtaining suitable mechanical properties for a selected theory, beam theory can be used to analyse structural elements. The degree of anisotropy of the composite material is one of the factors which the choice of beam theory depends on. The ratio of longitudinal-to-shear modulus is higher than isotropic materials which are displayed by composite materials. This ratio varies if there is an increase in the anisotropy degree of the material. For this reason shear deformation in the beam will increase as the anisotropy degree of the material increases.

To account for shear deformation, Timoshenko beam theory (TBT) gives a better estimation of the actual behaviour as contrast to the traditional Euler-beam theory. In TBT, the plane sections of the beam are assumed to remain plane, but no longer usual to the beam neutral axis. The maximum deflection is given by the expression.

$$
\begin{aligned}
& \delta=\left(\delta_{f}+\delta_{c}\right)_{x=L / 2}=\frac{W L^{3}}{48 E I_{y}}+\frac{W L}{4 G K_{y} 4} \\
& =\frac{W L^{3}}{48 E l_{y}}\left(1+\frac{12 E}{G K_{y}(L / r)^{2}}\right)
\end{aligned}
$$

Where $W$ is the applied vertical load, distributed at two different locations, $L$ is the span or the distance between the supports, $A$ is the sectional area and $I$ is the moment of inertia of the section with respect to $y$ axis; $E$ is the flexural elastic longitudinal modulus for isotropic material; $G$ is the shear modulus, and $K$ is the shear area coefficient. For beams made of composite materials, equivalent longitudinal and shear moduli, $E$ and $G$ are required in order to obtain the beam maximum deflection by means of Equation 1. The shear deformation should also be considered while calculating the deflection for a composite material. According to Tamizhamuthu [5] changes in the fibre orientation can increase the rigidity of the profile. Ganesan [6] has conducted studies on FRP frames which reveal that shear deformation plays a vital role in calculating the deflection.

\section{Classical laminate theory (CLT)}

The in-plane stiffness properties may be calculated using classical lamination theory, in which the pultruded plate is characterized by its in-plane extensional stiffness coefficients, $A_{i j}$. The in-plane engineering stiffness properties may be obtained from standard tests on coupons separated from the pultruded profile. In this approach, the laminate is considered to be homogeneous. Since the orthotropic plates, in the pultruded profile, are assumed to be homogeneous on a macro mechanics level, the plate flexural properties can be calculated from their inplane extensional engineering properties (obtained either from test data or from the in-plane extensional matrix).The orthotropic plate flexural rigidities (the equivalents of $E I$ per unit width for a beam) are given as:

$$
\begin{aligned}
& D_{L}=\frac{E_{L} t_{p}^{3}}{12\left(1-\mu_{L} \mu_{T}\right)} \\
& D_{T}=\frac{E_{T} t_{p}^{3}}{12\left(1-\mu_{L} \mu_{T}\right)} \\
& D_{L T}=\frac{\mu_{T} E_{L} t_{p}^{3}}{12\left(1-\mu_{L} \mu_{T}\right)}=\frac{\mu_{L} E_{L} t_{p}^{3}}{12\left(1-\mu_{L} \mu_{T}\right)} \\
& D_{S}=\frac{G_{L T} t_{p}^{3}}{12}
\end{aligned}
$$

Where, $D_{L}, D_{T}, D_{L T}$, and $D_{S}$ are the longitudinal, transverse, coupling, and shear flexural rigidities and $t_{p}$ : is the plate thickness. The flexural rigidities relate the plate bending moments (per unit length) to the plate curvatures Timoshenko and WoinowskyKrieger [7]. This notation is often used in analytical equations for pultruded profiles.

The in-plane strength properties may be obtained from theoretical calculations or from testing of coupons taken from the laminate, where the theoretical predictions are used, the first ply failure (FPF) is assumed to represent the strength of the 
laminate. Coupon testing is recommended for obtaining the strength properties for structural design.

\subsection{Flexural stiffness using CLT}

The flexural and shear stiffnesses can be computed based on the approximate classical laminate theory. Pultruded beams, orthotropic in nature, are approximated to be isotropic, in computing the flexural and shear rigidity. The influence of secondary directions is ignored. Nagaraj and GangaRao [8] suggest that the approximation can be used in rigidity computations.

Pultruded profiles are manufactured using fibre bundles and fibre mats arranged in layered sequence. Thus, a pultruded profile can be approximated to consist of different layers of fibre laminates of different thickness. A pultruded laminate consists of three stiffness terms, viz., extensional stiffness $\left(K_{e}\right)$, bending stiffness $\left(K_{b}\right)$, and bending-extension coupling stiffness $\left(K_{b e}\right)$. The bending-extension coupling stiffness is zero for symmetric laminates. The extensional stiffness $\left(K_{e}\right)$ and bending stiffness $\left(K_{b}\right)$ terms for a beam's flange and web are given by

Flange:

$A_{f}=b \sum_{r=1}^{N} E_{r} t_{r} ; \quad D_{f}=b \sum_{r=1}^{N} E_{r}\left[t_{r} z_{r}^{2}+\frac{t_{12}^{3}}{12}\right]$

Web:

$A_{w}=d \sum_{r=1}^{N} E_{r} t_{r} ; \quad D_{w}=\frac{d^{3}}{12} \sum_{r=1}^{N} E_{r} T_{r}$

Where $b$ : flange width; d: web depth; $E_{r}$ : elastic modulus of $r^{\text {th }}$ layer in the structural coordinate system; $t_{r}$ : thickness of $r^{\text {th }}$ layer and $Z_{r}$ : distance of the middle surfaces of $r^{\text {th }}$ layer from the middle surface of the laminate. $\mathrm{E}_{\mathrm{r}}$ represents the anisotropic modulus. The approximation of a laminate to be isotropic (i.e., $E_{1}=E_{2} ; \mu_{12}=\mu_{21} ; G_{12}=G$ ) eases the computation of $E_{r}$ required in $(5.54,5.55)$ and reduces the complexity of beam rigidity computations. The influence of secondary directions was not to be significant. Approximating the laminate to be isotropic $\left(E_{1}=E_{2} ; \mu_{12}=\mu_{21}\right)$ reduces to the form $E=E_{1}$

The procedure of theoretical evaluation of flexural stiffness can be explained as below:

Computation of elastic modulus of 900GSM Bi-axial mat (+45/-45deg)

Thickness of laminate per layer: $t$; Weight of fibre mat/sq.m: $W_{f}$; Density of glass fibre: $\rho_{f}$ Volume of glass fibre in Laminate: $\mathrm{Fv}=W_{f} f \rho f$; Volume of lamina: 234
$L_{v}$ Volume fraction of fibres: $V_{f}=F_{v} / L_{v} ; V_{m}$ Volume fraction of matrix Using the rule of mixtures the elastic modulus in the direction of fibres

$E_{1}=V_{f} E_{f}+V_{m} E_{m}$

Using Mechanics of materials

$\mathrm{E}_{2}=\frac{\left(E_{f} \times E_{m}\right)}{V_{f} \times E_{m}+V_{m} \times E_{f}}$

$\mathrm{G}_{12}=\frac{\left(G_{f} G_{m}\right)}{V_{m} \times G_{f}+V_{f} \times G_{m}}$

For +/- 45 deg., the mat is considered to be having two laminates. The elastic modulus can be multiplied by $\cos 45^{\circ}$. Similarly, the same procedure can be for calculating the properties of carbon mat of 300GSM density with uni-directional mat. For bi-directional mat, $50 \%$ of carbon fibre in zero deg. and $50 \%$ of carbon fibre in $90^{\circ}$. Therefore, the elastic modulus can be accounted for 150 GSM only.

The elastic modulus of glass rovings, the following procedure can be allotted with the following properties:

Length of fibre in $\mathrm{m} / \mathrm{kg}((1000 /($ tex/1000)); No. of bundles for each roving layer (n); Width of lamina $\left(W_{f}\right)$; Thickness of each layer $(\mathrm{t})$; Density of fibres $\left(\rho_{f}\right)$; Diameter of fibres $D_{\mathrm{f}}=\left(\sqrt{\frac{1}{\rho Y 9 \pi}}\right)$; Volume of fibre $V_{\mathrm{f}}=\frac{n \pi D^{2}}{4 b t} ;$ Volume fraction of matric $\left(V_{\mathrm{m}}=1-V_{\mathrm{f}}\right)$

Based on the above calculations, the elastic modulus is calculated for bi-axial mat, carbon mat and glass rovings as per the equation described in the subsequent studies.

The elastic modulus of glass rovings, the following procedure can be allotted with the following properties:

Length of fibre in $\mathrm{m} / \mathrm{kg}((1000 /($ tex/1000)); No. of bundles for each roving layer (n);Width of lamina $\left(W_{f}\right)$; Thickness of each layer $(\mathrm{t})$; Density of fibres $\left(\rho_{f}\right)$; Diameter of fibres $D_{\mathrm{f}}=\left(\sqrt{\frac{1}{\rho Y 9 \pi}}\right)$;Volume of fibre $V_{\mathrm{f}}=\frac{n \pi D^{2}}{4 b t} ;$ Volume fraction of matric $\left(V_{\mathrm{m}}=1-V_{\mathrm{f}}\right)$

Based on the above calculations, the elastic modulus is calculated for bi-axial mat, carbon mat and glass rovings as per the equation described in the subsequent studies.

$A_{f}=b\left(E_{1} t_{1}+E_{2} t_{2}+E_{3} t_{3}\right)$ 
$D_{w}=\frac{d^{3}}{12}\left(E_{1} t_{1}+E_{2} t_{2}+E_{3} t_{3}\right)$

Similarly, Shear rigidity $\mathrm{N}(\mathrm{kAG})$ can be calculated as

$k A G=d\left(G f_{1} t_{1}+G f_{2} t_{2}+G f_{3} t_{3}\right)$

Based on the above calculations the following values are for the six types of beams (Table 1).

Table 1 Theoretical computation of EI and kAG

\begin{tabular}{lll}
\hline Beam type & $\begin{array}{l}\mathbf{E I}\left(\mathbf{1 0}^{\mathbf{1 1}}\right) \\
\mathbf{N . m m ^ { 2 }}\end{array}$ & $\mathbf{N}\left(\mathbf{1 0}^{\mathbf{6}}\right)$ \\
\hline IBBM3MR & 6.227 & 4.039 \\
IBOUCL3MR & 7.204 & 4.039 \\
IBOBCL3MR & 6.716 & 4.039 \\
IBOUOBCL3MR & 7.693 & 4.039 \\
IBTUOBCL3MR & 8.67 & 4.039 \\
IBOUTBCL3MR & 8.181 & 4.039 \\
\hline
\end{tabular}

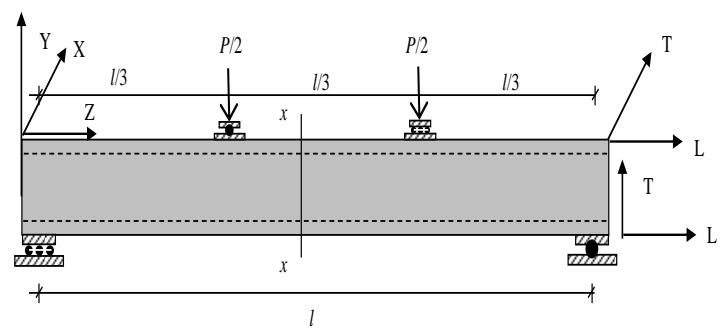

Figure 1 Local and global co-ordinates relationship for a pultruded profile

Figure 1 shows the local and global co-ordinates relationship for a pultruded profile.

\section{Experimental investigations}

4.1Preparation of GFRP I-beams along with CFRP laminates with different fibres orientations

All GFRP I-beams are manufactured using pultrusion process as per the ASTM D 4385-2013 standards and are designated as per the fibre orientations. Table 2 shows the designations of different beams. The experiment was carried out on six sets of FRP pultruded I Beams and all the beams of this category are manufactured and tested for a span of $3000 \mathrm{~mm}$. Such beams are held on simple supports i.e. one end has the roller support and the other end is hinged. Along the span direction, at six locations with equal intervals, the flanges of all the beams are restrained laterally for all sets of beams. The first set consists of two FRP pultruded I beams, of conventional type, without any CFRP laminates. It is designated as IBBM3MR.

The second set consists of two FRP pultruded I beams, with one layer of bi-directional mat both in the top and bottom flanges, and spanned over $3 \mathrm{~m}$ with the flanges which are restrained along the span. The flanges and the interjection between the flanges and web are reinforced with one layer of unidirectional $\left(0^{\circ}\right)$ CFRP laminates of 300 GSM. It is designated as IBOUCL3MR. The thickness of unidirectional laminates come around $0.3 \mathrm{~mm}$.

The third set consists of two FRP pultruded I beams, with one layer of bi-directional mat all along the outer surface and spanned over $3 \mathrm{~m}$ with the flanges which are restrained along the span. The flanges and the interjection between flanges and web are reinforced with one layer of bi-directional $\left(0^{\circ} / 90^{\circ}\right)$ CFRP laminates of 300GSM. It is designated as IBOBCL3MR. The thickness of the bi-directional laminate is $0.3 \mathrm{~mm}$.

The fourth set consists of two FRP Pultruded I beams, with one layer of bi-directional mat all along the outer surface and spanned over $3 \mathrm{~m}$ with the flanges which are restrained along the span. The flanges and the interjection between the flanges and web are reinforced with one layer of uni-directional and one layer of bi-directional CFRP laminates each of 300 GSM. It is designated as IBOUOBCL3MR. The overall thickness of both the laminate is $0.6 \mathrm{~mm}$.

The fifth set consists of two FRP Pultruded I beams, with one layer of bi-directional mat all along the outer surface and spanned over $3 \mathrm{~m}$ with the flanges which are restrained along the span. The flanges and the interjection between the flanges and web are reinforced with two layers of uni-directional and one layer of bi-directional CFRP laminates each of 300GSM. It is designated as IBTUOBCL3MR. The overall thickness of the laminate is $0.9 \mathrm{~mm}$.

The sixth set consists of two FRP Pultruded I beams, with one layer of bi-directional mat all around the outer surface and spanned over $3 \mathrm{~m}$ with the flanges which are restrained (FR) along the span. The flanges and the interjection between the flanges and web are reinforced with one layer of uni-directional and two layers of bi-directional CFRP laminates. It is designated as IBOUTBCL3MR. The overall thickness of the laminate is $0.9 \mathrm{~mm}$. 
Table 2 Beam with different designations for experimental analysis

\begin{tabular}{lllll}
\hline Profile of specimen & Type & FR & Span(mm) & No.S \\
\hline I-200 & IBBM3MR & $\mathrm{R}$ & 3000 & 2 \\
I-200 & IBOUCL3MR & $\mathrm{R}$ & 3000 & 2 \\
I-200 & IBOBCL3MR & $\mathrm{R}$ & 3000 & 2 \\
I-200 & IBOUOBCL3MR & $\mathrm{R}$ & 3000 & 2 \\
I-200 & IBTUOBCL3MR & $\mathrm{R}$ & 3000 & 2 \\
$\mathrm{I}-200$ & IBOUTBCL3MR & $\mathrm{R}$ & 3000 & 2 \\
\hline
\end{tabular}

All the pultruded I-beams used in this study have a uniform cross-section and a depth of $200 \mathrm{~mm}$. The pultruded I beams are manufactured by pultrusion process by Meena Fibreglas Industries, Pondicherry, India. Each beam has ECR glass rovings of 4800 tex (Owen Cornings India, Mumbai) with Isopthalic grade polyester resin (Ashland India, Mumbai). On the outer surface, bi-directional mat of $900 \mathrm{GSM}$ with $-45^{\circ} /+45^{\circ}$ direction fibre is used (Seartex India, Mumbai). A curing temperature of $140^{\circ} \mathrm{c}$ is maintained during the production. The post curing is done in a $4 \mathrm{~m}$ long oven, at $120^{\circ} \mathrm{c}$ for 4 hours (even though it is specified for profiles made using epoxy resin) to ensure complete cross linking of polymeric chain. Once it is post cured, all the specimens are fine cut to a required length using a diamond coated rotary blade. After the specimens are cut and they are inspected, visually for any defects as per ASTM D $4385-2013$.

The beams with CFRP laminates require additional surface preparation for applying CFRP laminate. The surface over which the carbon fibre applied is surfaced using a 80 grit coated disc using an angle grinder as shown in Figure 2. The surface preparation is necessary to enable the adequate bonding of carbon fibre over the FRP substrate. Carbon fibre roll form of standard $1 \mathrm{~m}$ width is cut by means of electrically operated scissors in order to prevent damage to the fibres.

The carbon fibre is cut to the required width and length and is placed over the FRP profile. The epoxy resin is applied manually over the carbon fibre. The first layer is placed over the section, when it is wet, the resin and hardener quantity is mixed and applied over the surface in order to create a proper bonding of the laminate. After applying each layer, the metal rollers with serration are rolled over the laminate, to remove the entrapped air. After applying all the layers, the surface is covered with a Mylar film and the surface is squeezed out with a rubber spatula, to remove the excess resin.
The beams are allowed to cure overnight and placed in an electric oven for post-curing, at $160^{\circ} \mathrm{C}$, for 6 hours. After the beams are removed, the edges are trimmed using an angle grinder. Then, the beams are despatched to the laboratory for testing.

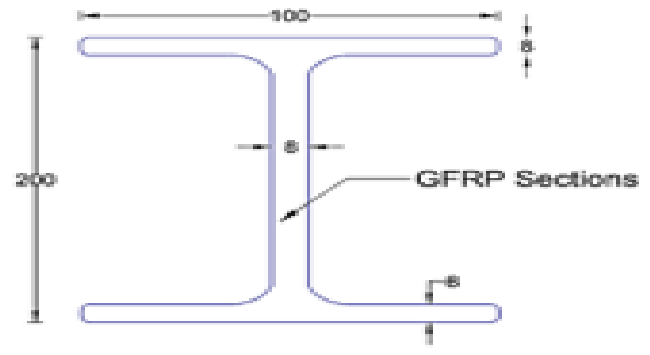

Figure 2 (a) (IBBM3MR)

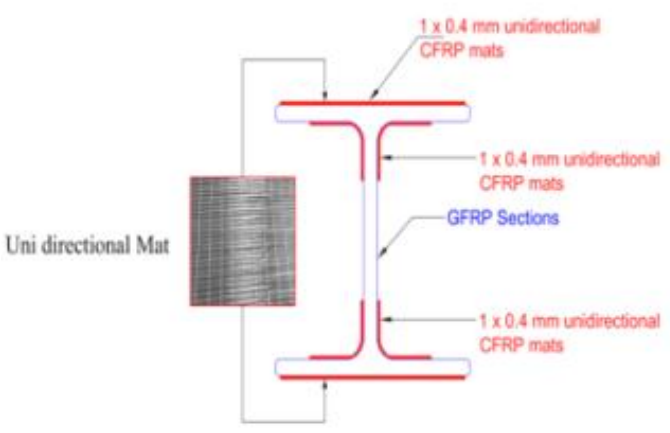

Figure 2 (b) IBOUCL3MR

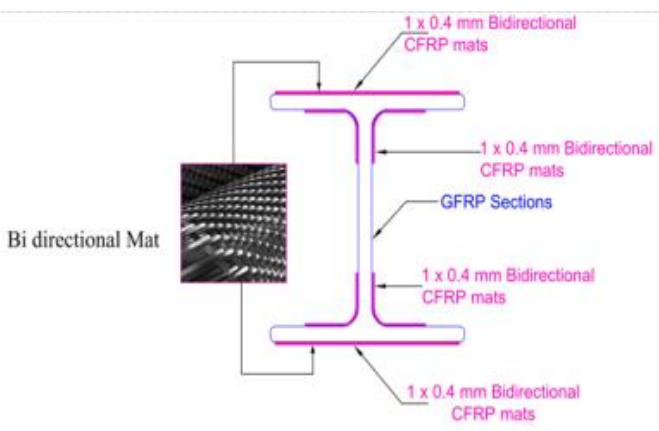

Figure 2 (c) IBOBCL3MR 


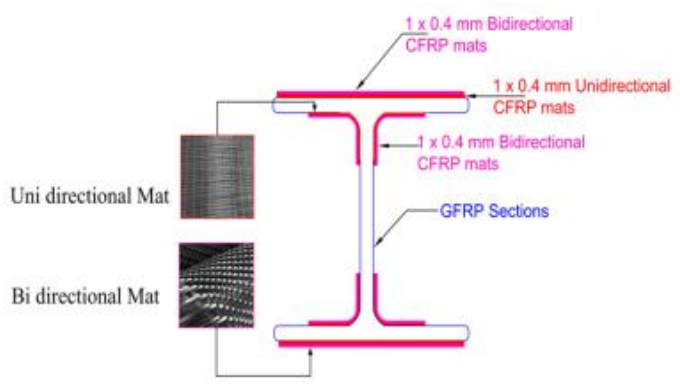

Figure 2 (d) IBOUOBCL3MR

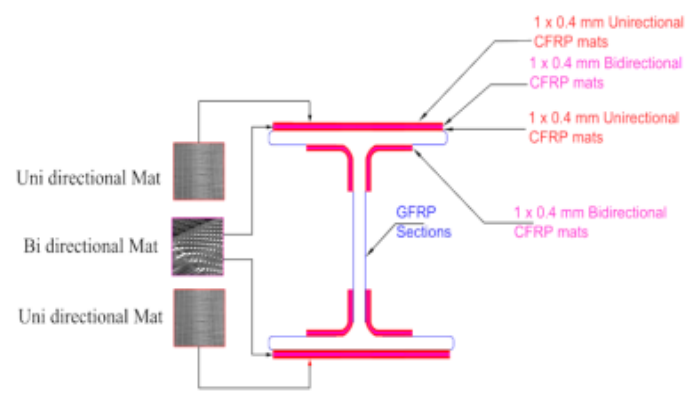

Figure 2 (e) IBOUOBCL3MR

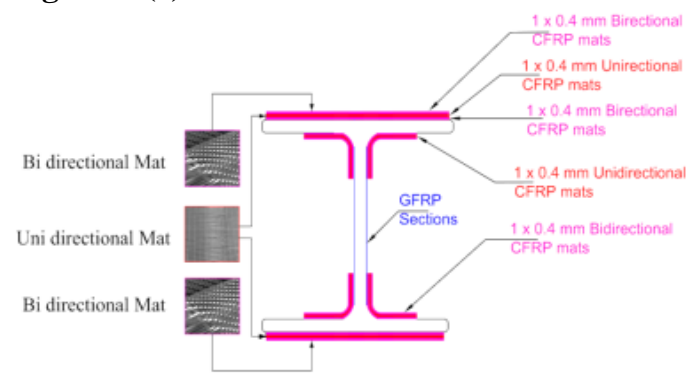

Figure 2 (f) IBOUYBCL3MR

\subsection{Test specimens}

The experimental program consists of totally twelve beams of $3000 \mathrm{~mm}$ span. All the twelve beams are tested for static load test. A schematic diagram of the test specimen is shown in Figure 3. The various beam parameters that are considered, in the present study, with their designations are presented in Table 3. All the beams are provided with the grid points to locate the loading points and strain measuring positions. Strain gauges are pasted to measure the strains using electrical strain gauges. In the next section, a detailed experimental setup is explained for three and four point bend test conditions.

\subsection{Test setup}

A load frame of $500 \mathrm{kN}$ capacity is used for testing the FRP pultruded I beams, strengthened with the CFRP laminates of different fibre orientations. The monotonically increasing static load is applied 237 physically through hydraulic jack of $300 \mathrm{kN}$ capacity. The load applied is measured with the proven ring which has a dial gauge. Steel pedestals of size $750 \mathrm{~mm} \times 750 \mathrm{~m}$ and $1000 \mathrm{~mm}$ height (Figure 4) are used to support the beams.

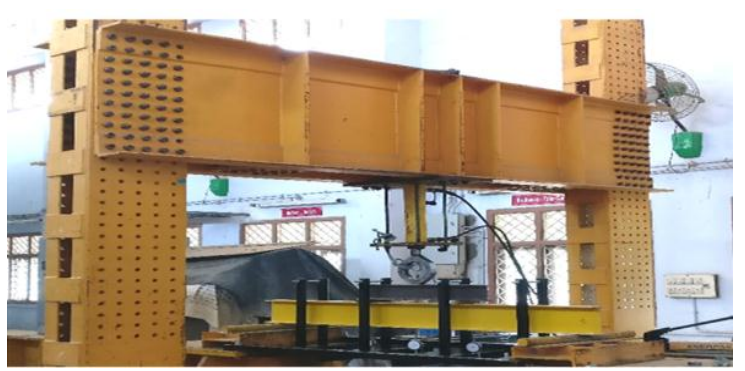

Figure 3 Loading frame

The supports are specially made to act as hinge and roller at the ends. A spreader beam of steel I-Beam of depth $125 \mathrm{~mm}$ is used with stiffened steel plates, near the load points, which can transmit the load from the proven ring to the beam.

Two point loading

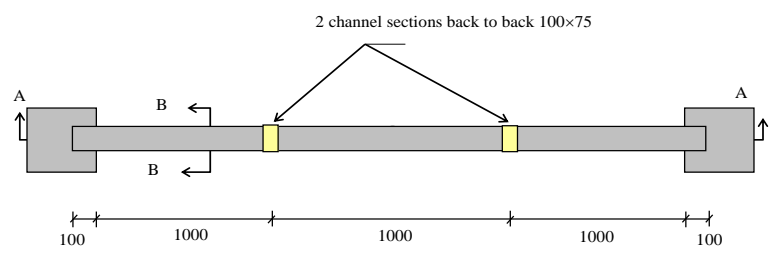

(a) Top view

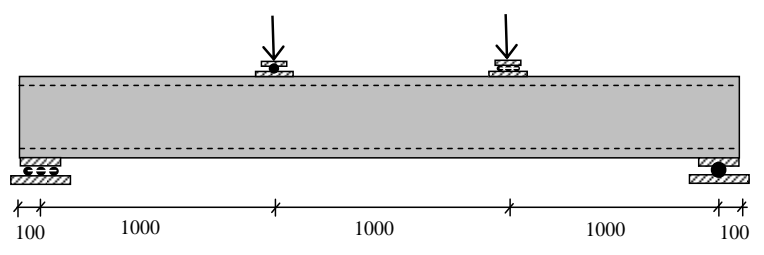

(b) Two point loading

Figure 4 Experimental test setup

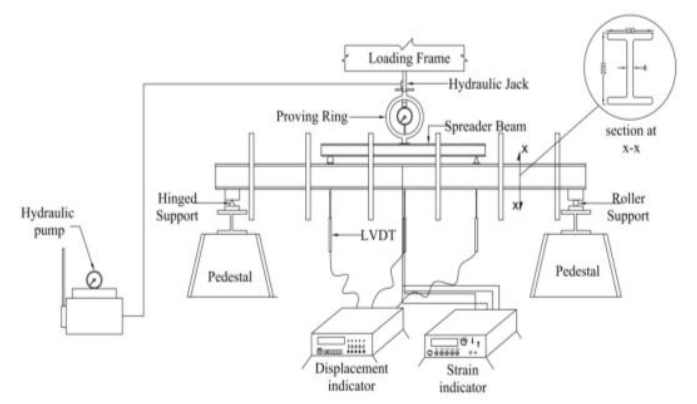

Figure 5 Schematic diagram of I-Beam with lateral restrains $(3 \mathrm{~m})$ 
Literature studies revealed that the use of additional lateral restrains can solve the problem of lateral torsional buckling.

Additional lateral restraints are given to the flanges along the span direction at six equal intervals of all the I-beams. This frame is fabricated using steel hollow tubes of $40 \mathrm{~mm} \times 40 \mathrm{~mm} \times 3 \mathrm{~mm}$ with $470 \mathrm{~mm}$ spacings. This entire frame is supported on saddle supports and it is isolated from beam supports. The schematic diagram of the frame setup is shown in Figure 5. The deformations are measured using the linear variable displacement transducer (LVDT) with a least count of $0.01 \mathrm{~mm}$ of $100 \mathrm{~mm}$ traverse length at three different places, viz., one-third span, mid span and two-third span. A standing adjustable frame is made to hold the LVDT at the required places. All the deformations are measured using a multi-channel digital data acquisition system.

In this experimental setup, the lateral restraints are introduced in order to access its flexural properties exactly. The previous study reveals that open sections are susceptible to lateral torsional buckling.

\subsection{Experimental observations}

All the specimens are tested in the loading frame and the necessary observations are made. The test observations are presented in the form of photographs (Figure 6 to Figure 10) and graphs in the following sections.
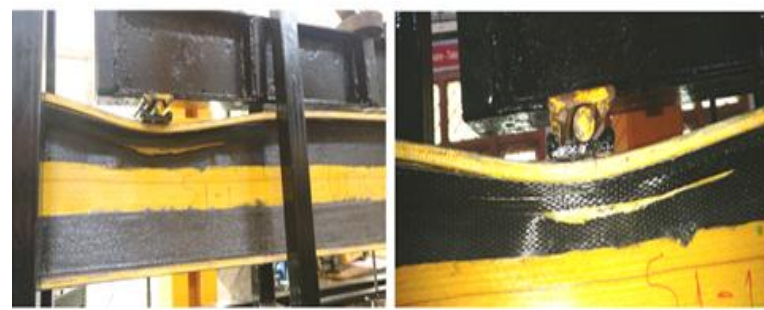

Figure 6 Failure of beam (IBOUCL3MR) due to fibre crushing at the flange and web joint in the compression flange
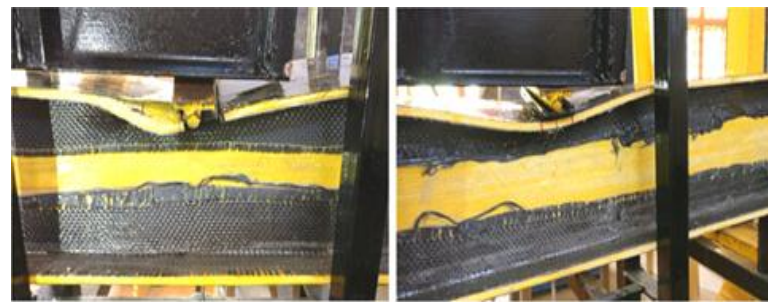

Figure 7 Failure of beam (IBOBCL3MR)
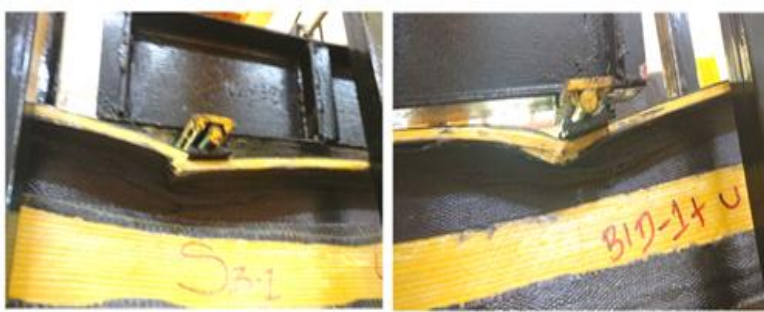

Figure 8 Failure of beam IBOUOBCL3MR (one layer of uni-directional mat and one layer of bidirectional mat)
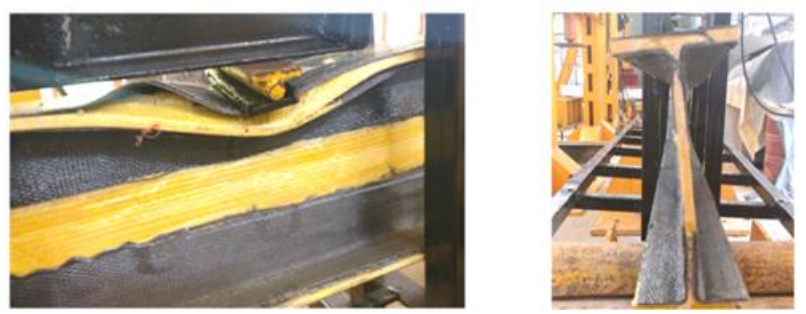

Figure 9 Failure of beam IBTUOBCL3MR (Two layers of uni-directional mat and one layer of bidirectional mat)
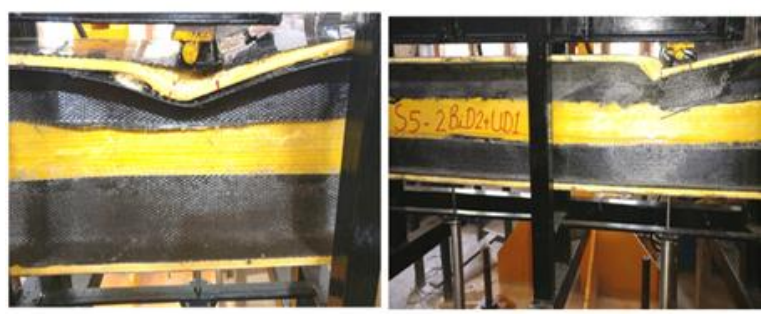

Figure 10 Closer view of the failure of beam IBOUTBCL3MR (One layer of uni-directional mat and two layers of bi-directional mat)

The experimental observations are presented in the forms of graphs (Figure 11 to Figure 18) for various beam parameters and are as follows:

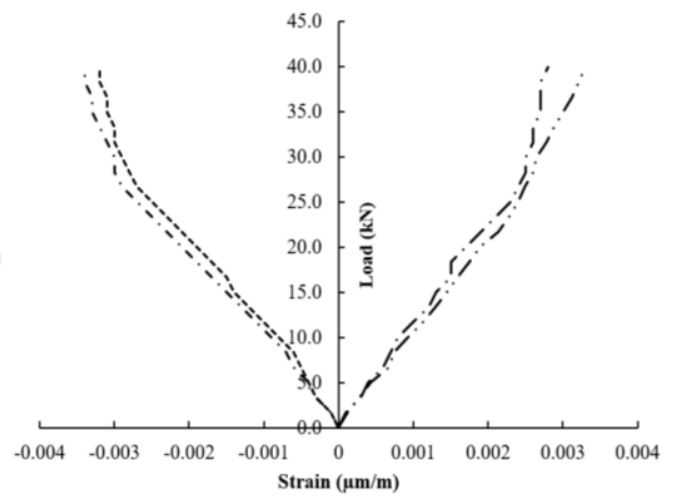

Figure 11 Load versus strain (IBBM3MR) 


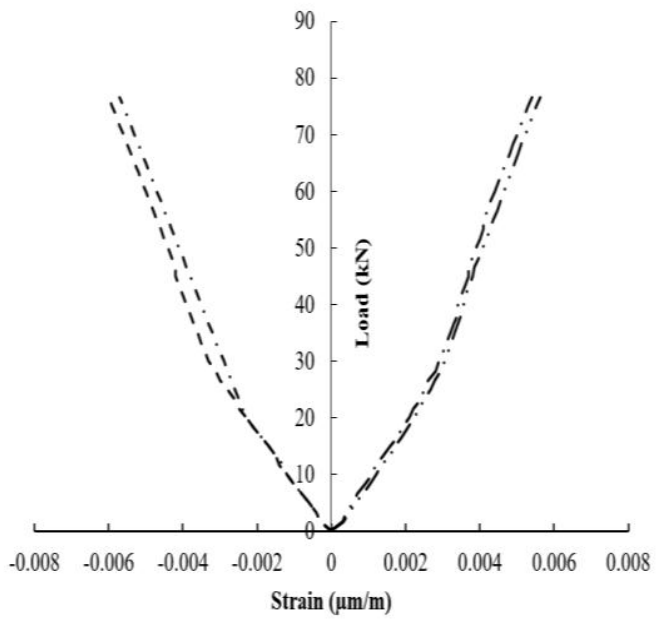

Figure 12 Load versus strain (IBOUCL3MR)

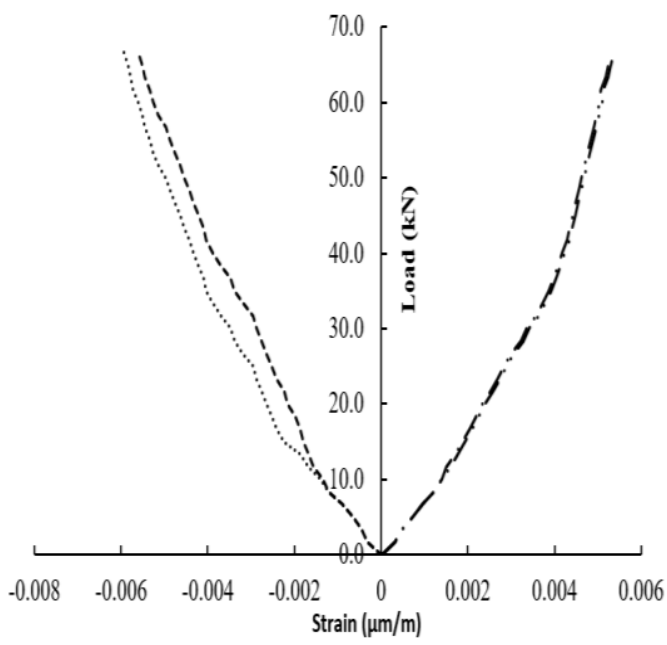

Figure 13 Load versus strain (IBOBCL3MR)

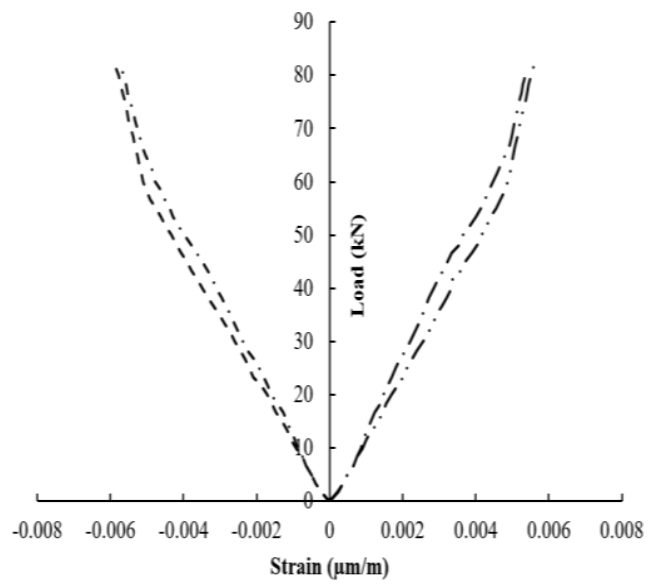

Figure 14 Load versus strain (IBOUOBCL3MR)

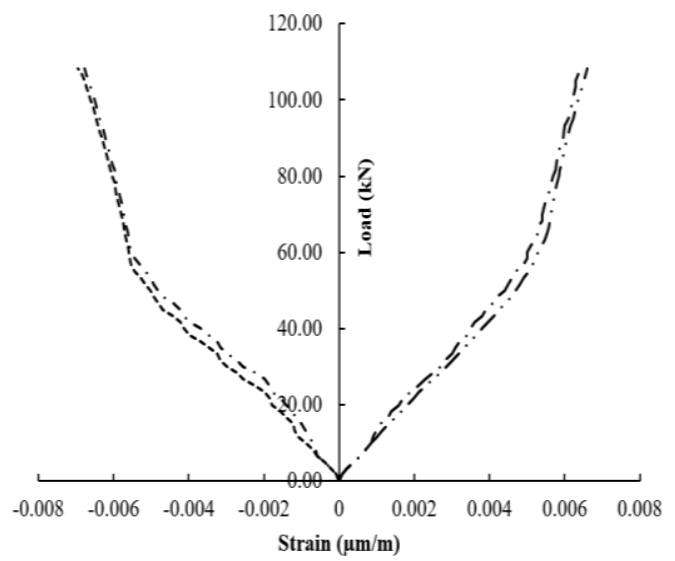

Figure 15 Load versus strain (IBTUOBCL3MR)

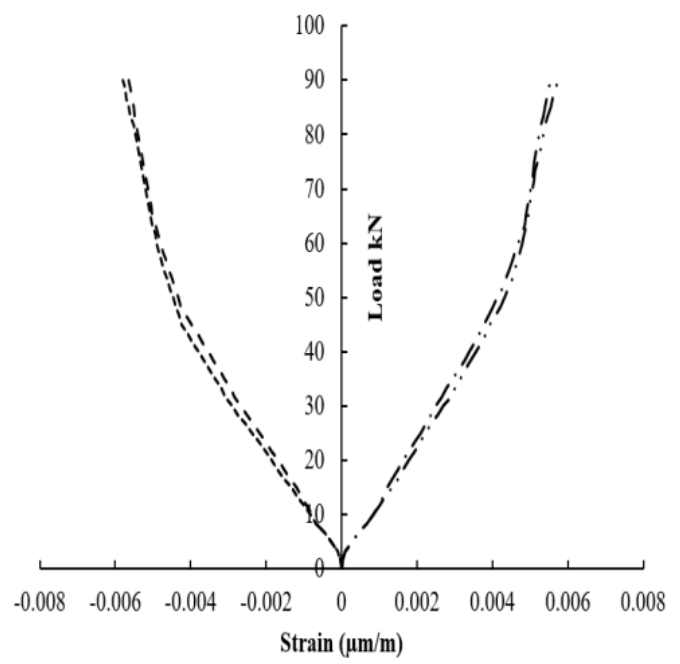

Figure 16 Load versus strain (IBOUTBCL3MR)

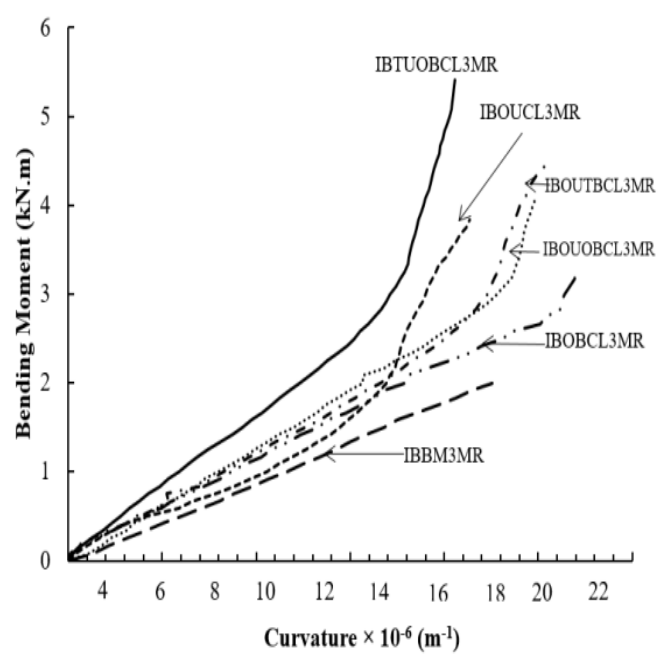

Figure 17 Moment versus curvature 


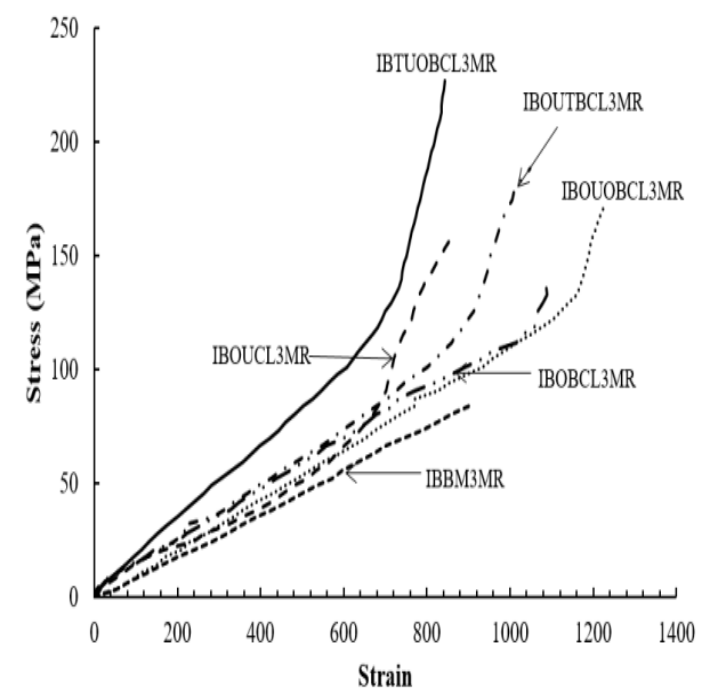

\section{Validation of theoretical computation} In order to validate the theoretical computation of shear stiffness (kAG) values by micro-mechanical approach, three point bending tests were carried out on all the six profiles. Experimentally, the shear stiffness was computed using Nagaraj and GangaRao [8] approach.

The expression for total deflection $\delta_{T}$ in the three point bending test is given by

$\delta_{T}=\frac{P L^{3}}{48 E I}+\frac{P L}{4 k A G}$

Where EI was obtained experimentally from the four point bending tests and by substituting $\delta_{T}$ and EI in the above expression, $\mathrm{kAG}$ is calculated and the results are compared with the theoretical values.

Figure 18 Stress versus strain

Table 3 Computation of kAG using experimental results

\begin{tabular}{|c|c|c|c|c|c|}
\hline BEAM & $E I \times 10^{11} N^{\prime} M^{2}$ & $\boldsymbol{\delta}_{T} \mathbf{M M}$ & kAG(E) $\mathrm{N} \times 10^{6}$ & kAG(T)N $\times 10^{6}$ & \% VARIATION \\
\hline IBBM3MR & 6.227 & 27.65 & 4.22 & 4.039 & 4.5 \\
\hline IBOUCL3MR & 7.204 & 53.1 & 4.39 & 4.039 & 8.7 \\
\hline IBOBCL3MR & 6.716 & 46.8 & 4.309 & 4.039 & 6.7 \\
\hline IBOUOBCL3MR & 7.693 & 51.25 & 4.44 & 4.039 & 9.9 \\
\hline IBTUOBCL3MR & 8.670 & 61.85 & 4.24 & 4.039 & 5.1 \\
\hline IBOUTBCL3MR & 8.181 & 53 & 4.41 & 4.039 & 9.2 \\
\hline
\end{tabular}

6.Comparison of theoretical and experimental results

The flexural stiffness of beams made of FRP pultruded I beams with and without CFRP laminates is evaluated experimentally and analytically. Comparison in terms of load mid span displacement curves, obtained from the 4-point bending test on beams is shown in Figures 19 to 24.

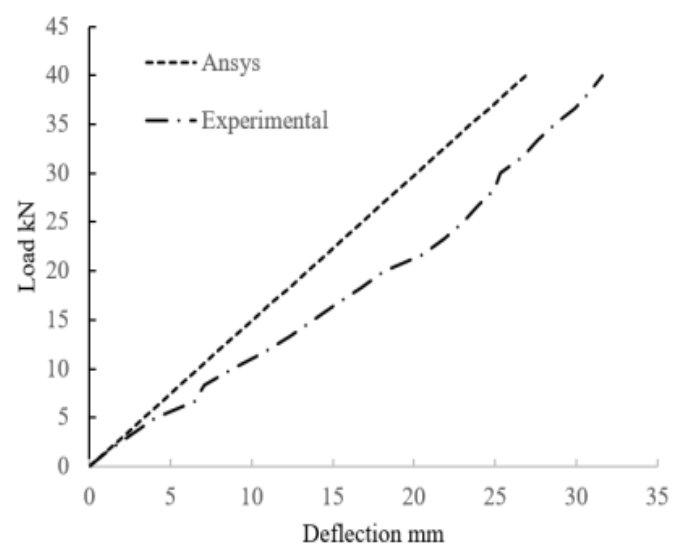

Figure 19 Load versus deflection (IBBM3MR)

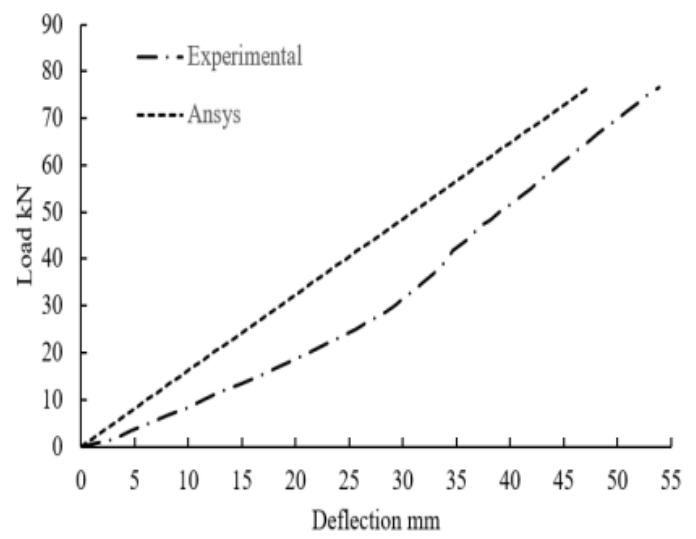

Figure 20 Load versus deflection (IBBM3MR)

The figures clearly states that the curves obtained experimentally and the straight lines obtained by TBT agree closely with the beam stiffness. It can be noted, from the figures, that the analytical results from TBT practically coincide with the experimental results for the beams with $3000 \mathrm{~mm}$ spans, corresponding to the ratio (L/D) ${ }^{2}$ as 225 . 


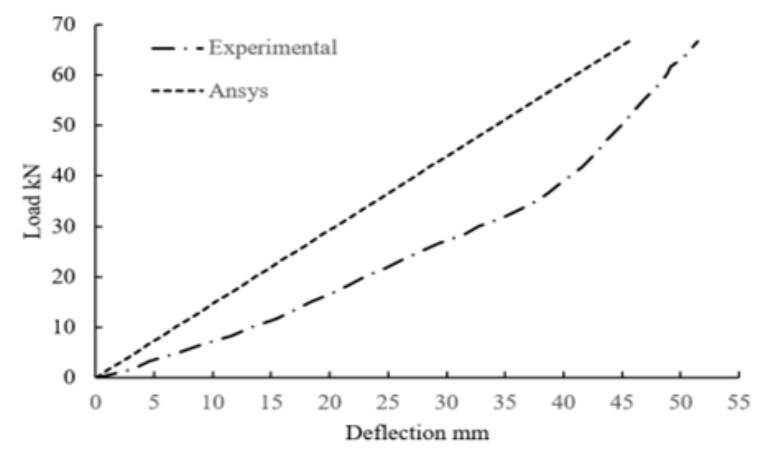

Figure 21 Load versus deflection (IBOBCL3MR)

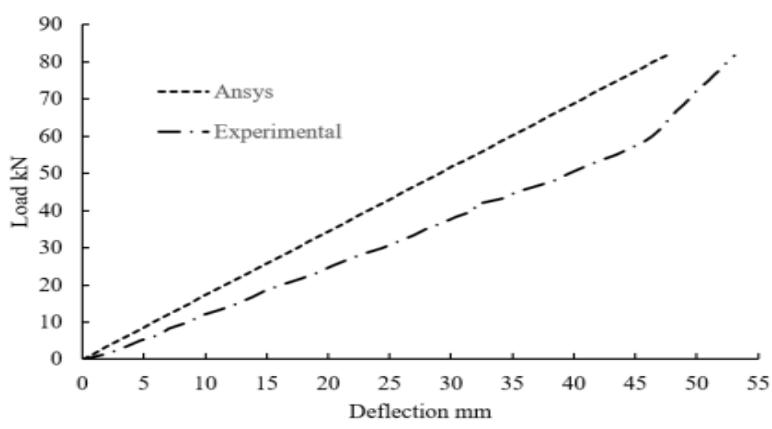

Figure 22 Load versus deflection (IBOUOBCL3MR)

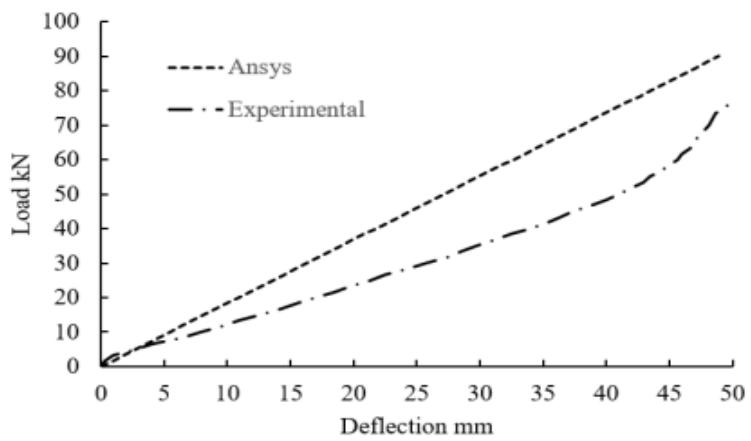

Figure 23 Load versus deflection (IBOUOBCL3MR)

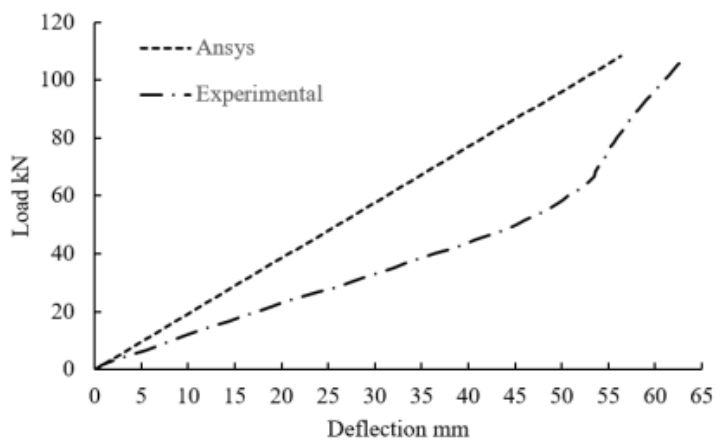

Figure 24 Load versus deflection (IBTUOBCL3MR)

In the experimental program, four-point and three point bend tests are initially performed initially. Two full scale I beam profiles were used. A methodology was used to obtain longitudinal and shear modulus of the section simultaneously. During the tests, considerable shear deformation was noticed in deflection along with linear elastic behavior for service loads.

Classic laminate theory, Rule of mixtures and Halphin and Tsai equations were used to arrive the mechanical properties of the profile material. Analysis of the GFRP beam was also carried out by finite element method (FEM) and TBT. The longitudinal elastic modulus was arrived by direction test and the values obtained are not close to the values obtained on full scale beam test.

Comparison of load-displacement curves, obtained, analytically and experimentally, shows a very good approximation of the FEM and TBT in relation to the experiments, for all beams. It can thus be concluded that in the design of beams with FRP pultruded I beams, the TBT with mechanical properties estimated by CLT can be used to evaluate the beam stiffness and verify deflections for service loads. However, for estimation of the mechanical properties, the individual properties of fibres and resin, the fibre volume fraction, and the composition of all laminates should be reasonably accurate.

On the other hand, the four-point bending test on full scale FRP profiles, besides being easy to implement experimentally, gives more reliable values to obtain the mechanical properties of the profile. It is, therefore, recommended for the evaluation of stiffness properties of pultruded beams with the CFRP laminates sections under bending, where the shear deformation contributes significantly to the final deformation value. Similar endings have also been noticed in the research carried out by [8-10]. Mentioning about the significance of verifying global unsteadiness modes in the design of open walled section is inevitable in this study. For the profile used in this study, the performed linear flexural analyses, using the FEM, is also necessary to verify the final limit state. However, since the FRP material displays high values of strength, the design is generally governed by limitation in deflections or by buckling of the sections.

\section{Conclusion}

In this study, the structural behaviour of GFRP pultruded profiles reinforced with CFRP laminates on the flanges is observed. The mechanical properties are obtained from the specimen extracted from the flanges. Tests of three-point and four-points twisting 
are conducted with different layup sequence of CFRP laminates, on full-scale models. The conclusions drawn are:

1. During the tests, considerable shear deformation was noticed in deflection along with linear elastic behavior for service loads.

2. Comparison of load-displacement curves, obtained analytically and experimentally, shows a very good approximation of the FEM and TBT in relation to the experiments, for all beams. It can thus be concluded that in the design of beams with FRP pultruded I beams, the TBT with mechanical properties estimated by CLT can be used to evaluate the beam stiffness and verify deflections for service loads.

3. The four-point bending test on full scale FRP profiles, besides being easy to implement experimentally, gives more reliable values to obtain the mechanical properties of the profile. It is, therefore, recommended for the evaluation of stiffness properties of pultruded beams with the CFRP laminates sections under bending, where the shear deformation contributes significantly to the final deformation value.

4. Since the FRP material displays high values of strength, the design is generally governed by limitation in deflections or by buckling of the sections.

Based on the discussions and analysis the following recommendations have been suggested for the future:

1. The geometric non linearity studies need to be considered.

2. The geometric imperfections of the profiles need to be considered and incorporated in the analysis.

3. Beams with wider flanges need to be experimentally evaluated, considering varying spans and the values of $\mathrm{E} \& \mathrm{G}$ need to be reevaluated.

\section{Acknowledgment}

None.

\section{Conflicts of interest}

The authors have no conflicts of interest to declare.

\section{References}

[1] Davalos JF, Qiao P. Analytical and experimental study of lateral and distortional buckling of FRP wide-flange beams. Journal of Composites for Construction. 1997; 1(4):150-9.

[2] Bank LC. Flexural and shear moduli of full-section fiber reinforced plastic (FRP) pultruded beams. Journal of Testing and Evaluation. 1989; 17(1):40-5.

[3] Meier U, Triantafillou TC, Deskovic N. Innovative design of FRP combined with concrete: short-term behaviour. Journal of Structural Engineering. 1995; 121(7):1069-78.

[4] Kumar P, Chandrashekhara K, Nanni A. Testing and evaluation of components for a composite bridge deck. Journal of Reinforced Plastics and Composites. 2003; 22(5):441-61.

[5] Tamizhamuthu S. Experimental and analytical investigations on the flexural behaviour of FRP pultruded I beam sections. M.E Structural Engineering Thesis Report. 2015.

[6] Ganesan G. Experimental study on the behaviour of telecommunication tower using FRP pultruded sections. M.E Structural Engineering Thesis Report. 2011.

[7] Timoshenko SP, Woinowsky-Krieger S. Theory of Plates and Shells. McGraw-Hill Education; 1959.

[8] Nagaraj V, GangaRao HV. Static behavior of pultruded GFRP beams. Journal of Composites for Construction. 1997; 1(3):120-9.

[9] Bank LC. Composites for construction: structural design with FRP materials. John Wiley \& Sons; 2006.

[10] Robert EM. Structural reliability analysis and prediction. John Wiley \& Sons; 1999.

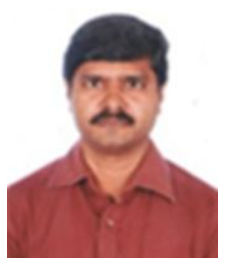

G.Ganesan is from Cuddalore and was born on 26.05.1969. He is a Post Graduate in Structural Engineering. He has an industrial experience of 25 years in the field of FRP and has executed many works involving FRP as the core material, like staircase, walkways and towers. Currently, he is heading the design and development of a leading FRP products manufacturing industry in the country. $\mathrm{He}$ is a fellow member of Institute of Engineers (India).

Email: ggnesan69@gmail.com

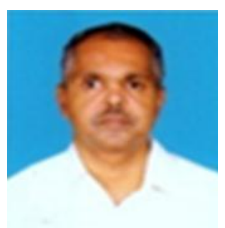

G.Kumaran is from Chidambaram and was born on 04.07.1968. He is a Doctorate in Structural Engineering and Professor of the Department of Structural Engineering, Faculty of Engineering and Technology, Annamalai University, Annamalai Nagar. He has published more than 15 papers in national and international journals. He has presented more than 8 papers at the national and international conference. He is a fellow member of Institute of Engineers (India). 